\title{
Pathology of Human Resource Management System in Iran's Ministry of Sports and Youth
}

\author{
${ }^{1}$ Mohammad Javadipour", ${ }^{2}$ Mohammad Hashemi Siavoshani, ${ }^{2}$ Mohammad \\ Hossein Ghorbani \\ ${ }^{1}$ Department of Curriculum Studies and Instruction, University of Tehran, Tehran, Iran. ${ }^{2}$ Sport \\ Management Department, Sport Science Research Institute, Tehran, Iran.
}

Submitted 06 August 2019; Accepted in final form 30 October 2019.

\begin{abstract}
Background. Today, having a strategic approach to human resources is essential. On this basis, identifying the strengths, weaknesses, opportunities, and threats of systems and processes of human resource management in any organization can influence its success or failure. Objectives. This study aimed to investigate the pathology of human resource management in Iran's Ministry of Sports and Youth. Methods. This study employed a mixed explorative (qualitative and quantitative) approach. The population in the qualitative part included two groups: the first group was the strategic committee that held with eight specialists; the second group included 23 participants selected through purposive sampling. Qualitative data collection to determine weaknesses, strengths, opportunities, and threats were fulfilled by studying documents and Semi-structured interviews. In the quantitative part, the population included 62 of all managers in the ministry of sports and youth (assistant directors, general managers, the chief of offices, advisors, as well as experts of the department of sports and youth in the human resource section). There were completed and analyzed 46 researcher-made closed questionnaires. In this study, qualitative data were analyzed through content analysis of high-level documents for extracting mission statements; critical factors of the scope statement, pivotal values, critical factors of performance and finally, for identifying S, W, O and T. Also, quantitative data were analyzed through descriptive statistics, middle and criterion deviation and perspective statistics and binomial tests. Results. In a qualitative study after analyzing the collected data 4 strengths, 51 weaknesses, 5 opportunities, and 7 threats of the Ministry were identified. In a quantitative study, the results showed all systems and processes of human resource management in Iran's Ministry of Sports and Youth should be renewed and modified based on scientific methods. Conclusion. In general, the result of this paper showed human resource management in Iran's Ministry of Sports and Youth is at WO situation. Therefore the mentioned organization should apply a conservative strategy to develop human resource management. Moreover, it showed that all five systems identified in the research (including Planning and supplying, Compensation and maintenance, Development of HR, Employee and labor relation, Leadership and organizational culture) should be renewed.
\end{abstract}

KEY WORDS: Human Resource Management, Sport, SWOT

\section{INTRODUCTION}

Today it is believed that human resources (HR), in comparison with natural resources and physical resources, are the most fundamental assets in an organization that play an essential role in an organization's success (1). HR is a department in organizations that resides in the knowledge, skills and motivation of employees. Accordingly, many organizations consider human

*. Corresponding Author:

Mohammad Javadipour, Associate Professor

E-mail: Javadipour@ut.ac.ir 
resources as an essential element in their competitive advantages, so they are seeking the best accurate and compatible systems for improving their HR policies $(2,3)$.

In sports organizations as service-based industries, effectiveness is also related to the quality and quantity of HR (4). There are three levels for the sport organization's success or failure: 1. individual level including employees, athletes, coaches and referees; 2. team level including working groups and sports teams; 3.organizational level including clubs, federations and other sport organizations that all of them are related to human assets (5). Sporting events play a significant role in the development of economic activities on the national and international scale in every country, and Sports organizations have become more competent over the years (6). Sports organizations must generally manage their time, energy loss, activities, money, and human resources to reach their goals (7). In particular, they must invest in their human resources for improving effectiveness and efficiency (8).

HR is a strategic approach that concentrates on what the aims of human resource management are and how they can be achieved. Human resource management (HRM) is the process for identifying the human resource requirements of an organization and planning for satisfying those requirements (9). Today organizations are working in an environment confronted by rapid changes and complexity, which led to increasing the challenges in front of them in their path to their goals (10). Therefore, organizations should apply the internal strategy for the management of external resources and the environment at the same time. Strategic planning is a vital management tool that enables the organization to deal with challenges efficiently and effectively and to control its resources and to respond to environmental changes successfully (11) HRM facilitate performance and development in organizations primarily through manageremployee interactions embedded in the process (12). HRM has a positive influence on managerial and stakeholder perceptions of organizational performance (13). It should be mentioned that HRM, as a process of creating values, includes different steps such as planning, recruitment, selection, retention and replacement, orientation, training and development, and appraisal and rewards (14).
Strategic planning is a formal managerial process involving a sequence of analytical and evaluative procedures that formulate an intended strategy and the means or method of implementing it while staying competitive (15). It is concerned with developing and improving an organization's mission, objectives, strategies, and policies which forms the basis of its communication with others to inform, motivate and involve them. Strategic planning serves as a framework for decision-making or securing support which ensures effective use of resources by focusing them on the key priorities. It enables an organization to monitor and evaluate the results and improve its performance (16).

The first step for the improvement of human resources management at any organization is to find its strategic situation (17). Recent studies have emphasized that there is a close relationship between human resources management and competitive performance (18). HRM at any organization should be renewed for increasing opportunities for the achievement of the objectives (18). De Pablos (2005) argued that organizations must replace themselves to be able to respond quickly to environmental demands (3). Because of the significant role of $\mathrm{HR}$ in organizations; identifying strengths, weaknesses, opportunities and threats is a necessary step for defining their strategies $(19,20)$

Iran's ministry of sports and youth, which is the leading organization for sports affairs, for various reasons, needs to pay more attention to its human resources and to identify its current situation. The most important reason is to support the organization's mission and strategic goals. The other purpose is researchers' findings that have shown HR is the most essential factor for the achievement of organizations' objectives and it helps to cope with the dynamic environment and contributes to growth and success. Moreover, HR practices affect product/service performance and financial performance.

The review of the related literature indicates that HR itself and its role have not been specified at sports organizations yet, perhaps because of their different essence $(21,22)$. Among the relatively relevant studies, the following studies can be mentioned: Lee and colleagues (2016) investigated the effects of HRM systems on three psychological states, namely, role breadth selfefficacy, felt responsibility for change, and trust in management. They found group creative 
processes can result in group innovation is facilitated by members' proactive behaviors (23). Aviso (2019) studied the problem of human resources planning due to the additional workforce requirements of research activities and developed a P-graph model as a decision support tool to aid in planning expansion of staffing levels for Higher Education Institutions (24). Al- Ayed (2019) studied the impact of strategic human resource management practices on organizational resilience. The results showed that the strategic value of human resource practices was the most influential variable on organizational resilience (25). Omer (2019) studied the role of SWOT analysis on strategic planning by Samsung Company. He found the essential impacts of SWOT analysis on the marketing strategic plan at this company (26) Motalebi Varakani (2016) studied the effect of strategic management of the human resources on the performance of the Islamic Republic of Iran Navy employees. The findings revealed that "careful employment," "human resource manager's participation in strategic decision-making process," "training of human resources," "human resource managers coordinated actions with the general policies," "communication among employees," and "information sharing "have been able to affect employee performance. Gholami (2017) used SWOT analysis stated that the proactive strategies of scientific and essential selection and evaluation of educated employees and increasing the capacity for recruiting specialized and empowered personnel, and the defensive strategy of systematization of the appointment and succession system based on merit are the most essential strategies for human resource planning (27). Shams and colleagues (2018) in their study mentioned that Among the indicators related to investment strategies, the use of experienced personnel, the place of the emergence of managerial changes and management instability, the existence of a large market for company products and the instability of laws in a country, respectively, were the most important strengths, weaknesses, opportunities and threats (28). The main findings of Javadipour and Rahbari (2018) showed that the organizational components, beliefs and cultures, economic conditions, scientific analysis and interpretation of studies were factors that affected the policy-making process of sport for all in Iran (29).
However, in Iran's Ministry of sports and youth, due to its particular standing, no study has been done for codifying a human resource plan. Thus, the present study aims at surveying strengths and weaknesses, opportunities and threats of human resource management at mentioned Ministry as a base for its HR strategy plan through using the SWOT model. For this purpose, a three steps model has been applied: first, to recognize missions; second, to determine strengths, weaknesses, opportunities and threats and third, to identify the current situation of systems and processes at Iran's Ministry of sports and youth.

\section{MATERIALS AND METHODS}

Research Design. This study employed a mixed explorative (qualitative and quantitative) method. Data Collecting and Sampling. The population in the qualitative part included two groups: the first group was the strategic committee that held with eight specialists and faculty members informed in the field of HRM; the second group included 23 participants selected through purposive sampling. In the first step, some related papers and six high documents including Iran- constitution, Islamic Republic of Iran's 20 year vision plan, Six Development Plan(2015), Acts of Parliament about amalgamation of Physical Education Organization and National Youth Organization (2010), governmental organization chart at State Management and Planning Organization, and organization chart of the Ministry of Sports and Youth were studied and the missions were identified through content analysis from the viewpoint of eight experts and faculty members. Data collection and determination of the weaknesses $(\mathrm{W})$, strengths $(\mathrm{S})$, opportunities $(\mathrm{O})$ and threats $(\mathrm{T})$ were fulfilled by studying documents and Semi-structured interviews. Data collection continued until theoretical saturation. The findings were provided to the participants and their opinions were inquired once again to confirm the validity and reliability of the data.

Tools. In the quantitative study, samples were62 all managers in the ministry of sports and youth (assistant directors, general managers, and the chief of the offices, advisors, as well as experts of the department of sports and youth in human resource section) who were scientifically and practically specialized in HRM field. Data was collected by using a research-made closed 
questionnaire that its items were made on the base of the findings of the qualitative study about $\mathrm{S}, \mathrm{W}$, $\mathrm{O}$ and $\mathrm{T}$. Within the evaluation, questionnaire were determined intervals from 0 to $20 \%$ poor (It is not observed), 21 to $40 \%$ below average (It is observed but should be renewed completely), 41 to $60 \%$ average (It is observed but should be renewed somewhat), 61 to $80 \%$ satisfactory (It is observed and supplies ultimately the ministry's needs), 81 to $100 \%$ perfect (It is observed and can be used as a model for other similar organizations). About 46 questionnaires was completed that were utilized for this study.

Validity and Reliability of the Instrument. Faculty members approved the face and content validity of the questionnaire in the field of sport management and strategic management. The reliability of the survey was determined through Cronbach's alpha.

Statistical Analysis. In this study, qualitative data were analyzed through content analysis of high-level documents for extracting mission statements; critical factors of the scope statement, pivotal values; critical factors of performance and finally, for identifying $\mathrm{S}, \mathrm{W}, \mathrm{O}$ and $\mathrm{T}$. Also, quantitative data were analyzed through descriptive statistics, middle and criterion deviation and perspective statistics, and binomial tests. The Friedman test was conducted to rank the data by utilizing SPSS software.

\section{RESULTS}

Qualitative study. This study tried to identify scope statements, missions, pivotal values, critical factors of performance, $\mathrm{S}, \mathrm{W}, \mathrm{O}$ and $\mathrm{T}$ of human resource management in Iran's Ministry of Sports and Youth. Findings of scope statement showed in 2025 human assets at Iran's Ministry of Sports and Youth will be knowledge-based, committed and creative who their merit, expert knowledge and organizational culture will be key factors for conducting missions. It was found that the most critical tasks of HRM at Iran's Ministry of Sports and Youth are: to supply HR based on reforming approach; to develop HR based on meritocracy approach; to evaluate the employees' performance; to select managers through meritocracy approach; to evaluate needs and to measure, plan and execute educational programs for employees and managers; to make an appropriate environment for the promotion of the HR knowledge and performance; to promote organizational culture; to develop the employees' welfare; to promote HR'S health and to develop the HR'S physical and mental skills; to promote the technical and scientific knowledge of HR.

Moreover, according to this study pivotal values are the growth of professional competency, maintain and promote ethical values, clearness in performance, justice; emphasis on doing team-work and commitment. Based on this study, critical factors of production are: supply, adjustment, and apply HR system; talent search, training and HR empowerment system; retention and compensation of HR system; and HR performance system. Then semistructured interviews based on EFQM excellence model and PCF model (Figures 1 and 2) were conducted with 23 experts, directors, general deputies, advisors and faculty members to collect the required data. Iran Association of human resource has classified Iran's EFQM model and it is widely used at Iranian organization. PCF model which is represented by American productivity and Quality Center, includes two groups of operational and support factors that cover more than 1500 processes and various activities. Through comparison, combination and analysis of these two models, five systems (themes) and 15 methods (categories) and their criteria were recognized in Iran's Ministry of Sports and Youth. In Table 1, these systems and processes are shown. After each interview, collected data were written in detail and the primary analysis and coding for each content were conducted through constant comparison. According to all meetings, principal codes were created. Then the similarity and conceptual relationship of thefundamental systems were surveyed and secondary systems were created. To confirm the validity and reliability of the data, the findings were provided to participants to inquire again about their opinions. Then the results were presented to experts and faculty members in a questionnaire to get their approval. Finally, based on the binomial test and Friedman test , 4 S, $51 \mathrm{~W}$, $5 \mathrm{O}$ and $7 \mathrm{~T}$ were identified. The ranking average of the S, main $\mathrm{W}, \mathrm{O}$ and $\mathrm{T}$ in the Ministry of Sports and Youth according to Friedman test is shown in Table 2. 

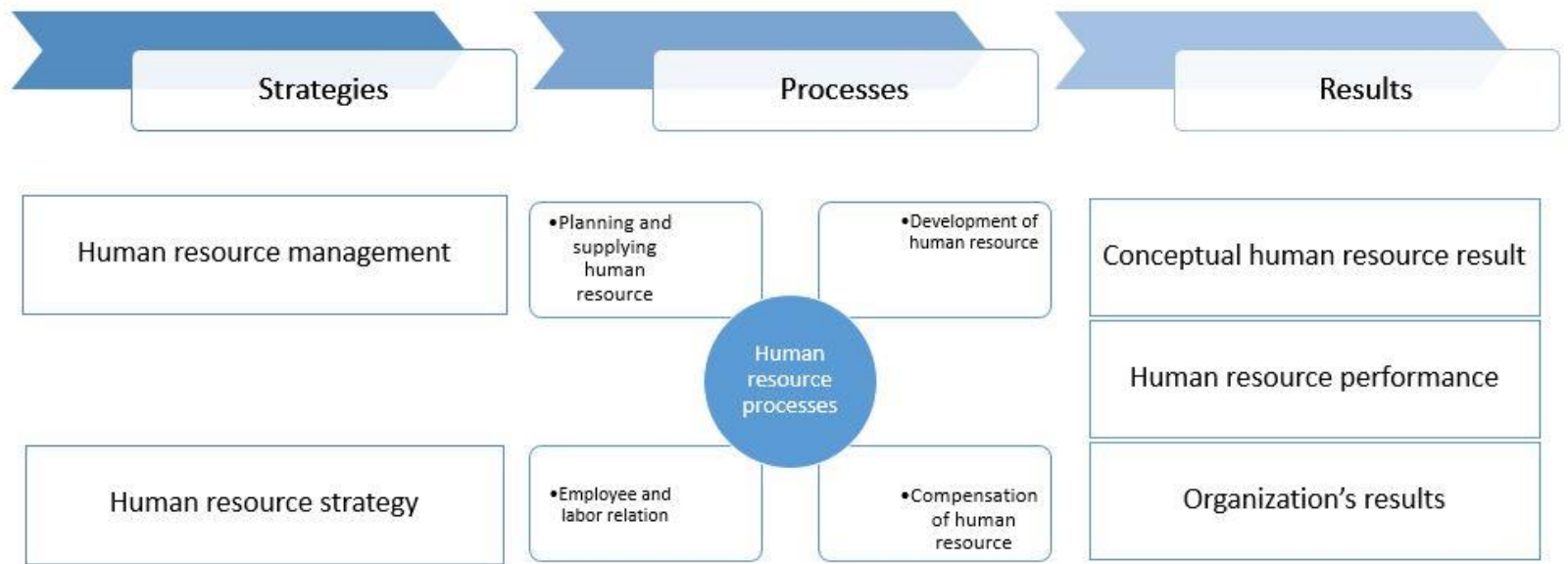

Human resource strategy

\section{Learning and Innovation}

Figure 1. Iran's Efqm Model (Iran Association of Human Resource, 2019)

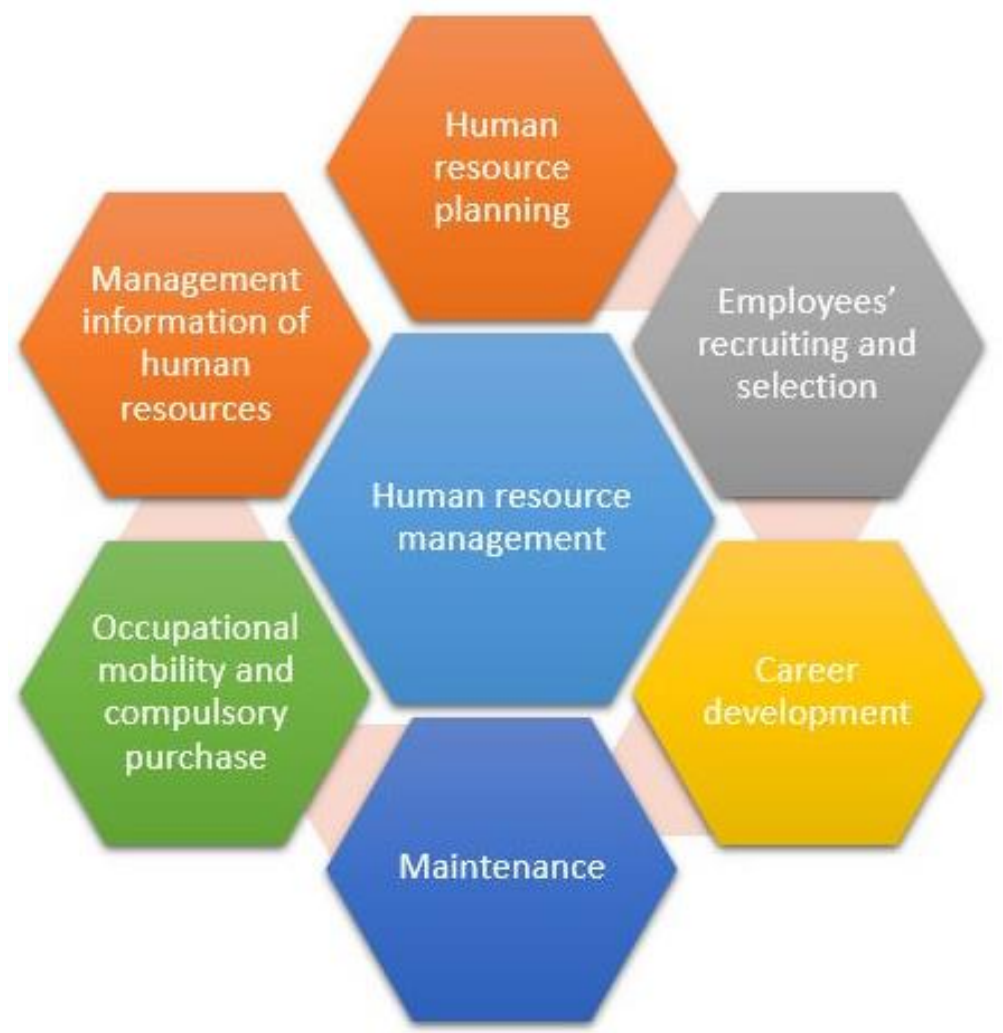

Figure 2. Pcf model (American Productivity and Quality Center, 2019)

Table 1. Systems and Processes at Iran's Ministry Of Sports and Youth

Systems

Planning and supplying

Compensation and maintenance

Development of HR

Employee and labor relation Leadership and organizational culture
Processes

Planning for labor supply Job design and analysis Selection and recruiting

Compensation, wage, privilege Employees' motivation

Staff training and management Planning career path and substitution Performance appraisal Immunity and health management

Relation Structure and organization chart Exit (retirement, dismiss) Communication and interaction Culture Leadership and the model of management Organizational culture Conceptual results (commitment, dependence, satisfaction) 
Table 2. The Ranking average of the S, W, O, T of Iran's Ministry of Sports and Youth

\begin{tabular}{|c|c|}
\hline S, W, O.T & Ranking Average \\
\hline Existence of skilled and expert employees & 3.78 \\
\hline Employees' motivation for learning & 3.43 \\
\hline Employees' high motivation for promotion & 3.18 \\
\hline possibility of contributing to training and learning & 3.23 \\
\hline Weakness in organizing HR & 27.99 \\
\hline Weakness in coordination between Job \& Jobholder & 23.82 \\
\hline Weakness in estimating the need for expert HR. & 26.76 \\
\hline Lack of job description & 29.73 \\
\hline Lack of system of recruitment & 30.78 \\
\hline In comparison with other similar organizations, payments are not satisfactory & 33.22 \\
\hline The emergence of employee-based culture & 17.94 \\
\hline Lack of a system for persuasions & 32.31 \\
\hline Ambiguity in goals and job function & 23.23 \\
\hline Lack of job security & 25.83 \\
\hline Low effectiveness of the current training courses & 24.50 \\
\hline Weakness in estimating the training needs & 24.54 \\
\hline Lack of knowledge management system & 30.01 \\
\hline Ambiguity in job promotion path & 27.01 \\
\hline Lack of succession & 30.78 \\
\hline Weakness in classifying HR information & 21.67 \\
\hline Lack of clear and documented job goals & 24.13 \\
\hline Lack of a modern system for employees' performance appraisal & 34.36 \\
\hline Weakness in the analysis of employees' performance & 25.45 \\
\hline Lack of coordination between current $\mathrm{HR}$ and Organization chart & 20.69 \\
\hline Weakness in planning a system for the management of HR Exit & 27.71 \\
\hline Weakness in developing a communication method for knowledge sharing & 29.68 \\
\hline Lack of codified strategic plan for HR & 29.68 \\
\hline Lack of a codified organization culture & 31.24 \\
\hline Weakness in the development of Teamwork & 30.41 \\
\hline Lack of a continues assessment of employees' welfare needs & 30.79 \\
\hline Lack of a continues assessment Of employees' satisfaction and Commitment & 31.46 \\
\hline Lack of a model for competency & 30.76 \\
\hline Possibility of the exit of key employees & 22.85 \\
\hline Possibility of working together with universities & 3.44 \\
\hline Development of communication technologies & 3.44 \\
\hline Development of office automation system & 4.04 \\
\hline The existence of junior and expert people in society & 4.06 \\
\hline The high position of the organization in Iran's society & 3.14 \\
\hline Low amount of salary at the Ministry & 4.41 \\
\hline Different attitudes of new generations of human resource & 3.85 \\
\hline Increasing human resource cost because of inflation & 3.65 \\
\hline Low welfare services to employees & 4.12 \\
\hline Development of knowledge & 3.56 \\
\hline The external effort for recruitment & 3.85 \\
\hline The effect of inflation on human resources' performance & 4.56 \\
\hline
\end{tabular}

Quantitative study. The results showed the criteria's score of processes: planning for labor supply, employees' motivation, staff training and management, planning career path and substitution, Performance appraisal, Organizational culture, and Conceptual results were lower than $40 \%$. The maximum gained score was $48.6 \%$ for the process of structure and organization chart and the minimum achieved score was $30.3 \%$ for the operation of Planning career path and substitution. Finally, on the base of the gained results, the situation of Iran's Ministry of Sport and Youth was specified using SWOT model (Table 3). The findings of EFE showed that the whole score of external factors equals 2.80 which means HRM externally tends to opportunities; on the other hand, IFE results showed a score of 1.71 , which means HRM at Ministry of Sports and Youth internally is at the situation of weakness. On the whole, HRM at the Ministry of Sports and Youth is at WO situation. Therefore the mentioned organization should apply conservative strategy to develop HRM. The proposed policies are: to improve managers' and employees' knowledge and professional competence; to develop career path; to develop performance appraisal system and retention and compensation of HR system; to develop organizational culture and to institutionalize professional ethics; to improve HR and to develop the appropriateness between job and jobholder. 


\begin{tabular}{|c|c|c|}
\hline Internal conditions & $\mathbf{S}$ & W \\
\hline & $\begin{array}{l}\text { existence of skilled and } \\
\text { expert employees } \\
\text {.employees' motivation } \\
\text { for learning } \\
\text {.employees' } \\
\text { motivation for promotion } \\
\text {.possibility of } \\
\text { contributing in training } \\
\text { and learning }\end{array}$ & $\begin{array}{l}\text {. Ambiguity in job promotion path } \\
\text {. Lack of proper tools and method for measuring employees' } \\
\text { Commitment satisfaction and motivation. } \\
\text {. Lack of a model for competency } \\
\text {.Weakness in informing employees of their situation for promotion } \\
\text {.Weakness in training Ministry's employees for managerial post } \\
\text {. Weakness in coordination between Job\& Jobholder } \\
\text {. Weakness in estimating the need for expert HR } \\
\text {.Weakness in improving job methods } \\
\text {. Lack of coordination between current HR and Organization chart } \\
\text {. Lack of job security } \\
\text {.Weakness in developing a communication method for knowledge } \\
\text { sharing } \\
\text {.Weakness in creating a sport spirit among employees } \\
\text {.Lack of codified strategic plan for HR } \\
\text {. Lack of plan for the development of professional ethics } \\
\text {.Lack of a codified moral and behavioral instruction } \\
\text {. Lack of a codified organization culture } \\
\text {. Weakness in planning a system for the management of HR Exit } \\
\text {.Lack of a separate system for recruitment } \\
\text {. Possibility of the exit of key employees }\end{array}$ \\
\hline $\mathbf{O}$ & So & Wo \\
\hline $\begin{array}{l}\text {. possibility for working together with } \\
\text { universities and research centers } \\
\text { development of information and } \\
\text { communication technologies } \\
\text {. development of office automation system } \\
\text {.the existence of junior and expert people in } \\
\text { society } \\
\text {.high position of organization in Iran's } \\
\text { society }\end{array}$ & $\begin{array}{lr}\text { to develop managers' and } \\
\text { employees' } & \text { knowledge } \\
\text { and } & \text { professional } \\
\text { competency } & \end{array}$ & $\begin{array}{l}\text {.to develop managers' and employees' knowledge and professional } \\
\text { competency } \\
\text {.to develop career path } \\
\text {.to develop performance appraisal system and retention and } \\
\text { compensation of HR system } \\
\text {.to develop organizational culture and to institutionalize } \\
\text { professional ethics } \\
\text {.to improve the HR and to develop the appropriateness between job } \\
\text { and jobholder }\end{array}$ \\
\hline $\begin{array}{l}\text {. } \mathbf{T} \\
\text { com amount of salary at Ministry in } \\
\text {.different attitudes of new generations of } \\
\text { human resource } \\
\text {.increasing human resource cost because of } \\
\text { inflation } \\
\text {.low welfare services to employees } \\
\text { increasing development of knowledge } \\
\text {.external effort for recruitment in the } \\
\text { Ministry } \\
\text { the effect of inflation on human resources' } \\
\text { performance }\end{array}$ & \begin{tabular}{ll}
\multicolumn{2}{c}{ ST } \\
To develop & HR \\
maintenance & and \\
compensation system &
\end{tabular} & $\begin{array}{c}\text { WT } \\
\text { To design HR maintenance and compensation system }\end{array}$ \\
\hline
\end{tabular}

\section{DISCUSSION}

During recent decades, because of rapid changes and increasing competition and globalization in technology and market throughout the world, all organizations _including sport organizations_ need to identify and codify their strategies and especially their HRM strategies to overcome confronting challenges (5).

In the present research, through the use of mixed-method, it was attempted to study the pathology of HRM at Iran's Ministry of Sports and Youth and investigate the most appropriate policy-making processes. About HRM at sports organizations, no study has been done in Iran, so it was attempted to study some foreign researches and also some relatively related internal investigations. For this purpose, the first Ministry's critical factors of the scope statement, missions, pivotal values and critical factors of performance were identified and then 5 systems and 15 processes were presented. Finally, by measuring the organization's situation according to participants' views and SWOT model, it was found that most of the Ministry's HRM processes are far from the ideal situation. This shows it is essential for the ministry to renew its plans and codify a strategic HR plan. This finding is inconsistent with the results of the study conducted by Cinar and Karcioglu (2013) that showed a suitable personnel strategy is essential for an organization's success (30). Therefore, according to the findings of this study five strategies and fourteen strategic planning were proposed. On the base of studying and content analysis documents, the most important missions of Ministry's HRM are attraction; development; retaining; and employing $\mathrm{HR}$ that through 
applying an active and updated plan, can supply Ministry's needs. This study showed that in 2025 human assets at Iran's Ministry of Sports and Youth will be knowledge-based, committed and creative who their competence, expert knowledge, and organizational culture will be critical factors for conducting missions. By considering the current situation. HR development system including staff training and management, planning career path and substitution performance appraisal, immunity and health management, is suffering from more weaknesses than the other methods. This means that the Ministry needs a healthy HR development. So the staff's performance evaluation and training, especially concerning knowledge sharing, must be continuously done. This finding is consistent with the result of the study done by Gholipour Souteh (2018) that indicated the relationship between human resources management and knowledge sharing in the ministry (31).

Weaknesses as lack of a system for employees' empowerment and development of employees' competence; lack of a model for competence; lack of clear and documented job goals.; lack of knowledge management system in one hand; Weakness in estimating the training needs; and opportunities as possibility for working together with universities and research centers; development of information and communication technologies; development of office automation system; and strengths as the employees' interest for learning and improving their knowledge and skills; and employees' high motivation for promoting, on the other hand, showed the importance of knowledge development. According to these findings, the first strategy was proposed as "to develop managers' and employees' knowledge and professional competence." Also, three strategic planning were identified including" designing and applying a comprehensive training system"; "designing and using knowledge management system," and "designing competency models for managers and employees" for the fulfillment of this strategy.

Weaknesses such as ambiguity in job promotion path; planning a system for the management of HR exit; possibility of the door of critical employees have affected on employees' motivation and satisfaction in one hand; chance for working together with universities and research centers; development of information and communication technologies; development of office automation system, on the other hand, are opportunities that can help to the elimination of mentioned weaknesses. Therefore, the strategy "to develop career path" was suggested. To conduct this strategy, two strategic planning was provided:" to design a comprehensive electronic promotion system" and "to design a system of aptitude research and succession".

According to weaknesses as lack of a continues assessment of employees' satisfaction and commitment; lack of a modern system for employees' performance appraisal; lack of job security; weakness in coordination between Job \& Jobholder; low payments; lack of codified strategic plan for HR; lack of coordination between current HR and organization chart and opportunities as possibility for working together with universities and research centers; development of information and communication technologies and availability of communication equipment; development of office automation system; strategy "to develop performance appraisal system and retention and compensation of HR system" was proposed. Threats such as the amounts of employees' payments and facilities in comparison with other organizations, applying ministry's employees by external institutions; the effects of inflation on employees' life have been considered for this strategy. It provides a careful performance appraisal that is related to motivation and compensation systems. According to the study three strategic planning are needed for coming exact this strategy:" to design an employees' motivation system based on internal and external motivations"; "to design and conduct HR performance management system related to compensation system"; "to apply appropriate policies in supplying Ministry's budget to increase payments and wages".

Weaknesses such as lack of a sports spirit among employees; lack of a plan for developing professional ethics; lack of codified organization culture.; emergence of employee dominance culture at Ministry; lack of the spirit of teamwork; weakness in developing a communication method for knowledge sharing; and opportunities such as possibility for working together with universities and research centers; development of information and communication technologies and availability of communication equipment; development of office automation system resulted to the 
suggestion of the strategy " to develop organizational culture and to institutionalize professional ethics." For conducting this strategy, "pathology and improvement of organizational culture and providing employees' code of conduct and behavior" were proposed as strategic planning. Some researchers have mentioned lack of a codified organizational culture as one of the main weakness in their studies (32-35). In this study also the mentioned weakness considered as one of the most critical weaknesses at the Ministry; so this weakness can be considered as a common challenge in all organizations. It was also found that leadership and organizational culture is far from a suitable position. Various researchers (36-38) have indicated the critical role of corporate culture in the improvement of an organization. So it is vital for the ministry's managers to try to eliminate this weakness.

In this study weaknesses including lack of a careful and scientific method for surveying the HR's current situation inappropriateness between jobs and jobholders, in other words, weakness in HR's systematic organizing; lack of codified strategic plan for HR; weakness in planning a system for the management of HR exit; incompatibility between current human resources and organization chart and conflict between existing human resources' situation and government policies in organizing and adjustment HR; lack of systematic methods for HR's systems(recruitment, selection, training systems)have provided some problems in HR section; but opportunities such as possible for working together with universities and research centers; the existence of junior and expert people in society; the Ministry's public image can help to eliminate the above weaknesses. For this reason, the strategy "to improve HR and to develop the appropriateness between job and jobholder" was proposed. This strategy includes "to design a comprehensive electronic HR's information bank; "careful job analysis"; 'to design recruitment system'; 'to renew organization chart with a look of agility'; 'to improve HR's activities", as its strategic planning.

According to the participant's view of this study employee and labor relation system, including structure and organization chart, exit, communication and interaction among staff and managers, is somewhat satisfactory. This means employees work in a friendly environment, so in the globally competitive, they are loyal to the organization and work with full interest. This finding is in constituent with Aslam's discovery that showed there would be a changing relationship between employee and employer in the organizations of the $21^{\text {st }}$ century (39).

\section{CONCLUSION}

In general, the result of this paper showed HRM in Iran's Ministry of Sport and Youth is at WO situation. Therefore the mentioned organization should apply conservative strategy to develop HRM. Moreover, it showed that all 5 systems identified in the research should be renewed. This study was conducted for the first time in Iran's sports organizations. Before this study, the situation of sports organizations and especially the situation of the Ministry of Sports and Youth were not surveyed. So it is believed that this paper will help the sports organizations' managers to improve the HR plan for achieving the organization's goals. Because of the relation among the Ministry of Sports and Youth and federations and clubs, the results of this study can be helpful for surveying and codifying their strategic human resource management with the help of experts and specialists of the Ministry and faculty members at universities. It should be mentioned that the lack of similar study at sports organizations was the main limitation, so it is a suitable field for researchers.

\section{Applicable Remarks}

- It is suggested for Iran's Ministry of Sports and Youth to coordinate with government and related organizations that are responsible for recruitment to apply knowledge-based, commitment, creative, and skilled human resources. The management team of this center, should design ways for training current employees to achieve national and international success.

- The managers of the mentioned organization should try their best to create a suitable organization culture to achieve its long-term goals, mission, and scope. 


\section{REFERENCES}

1. Collins CJ, Smith KG. Knowledge Exchange and Combination: The Role of Human Resource Practices in the Performance of High-Technology Firms. Acad Manage J. 2006;49(3):544-560. doi: 10.5465/amj.2006.21794671

2. Nikandrou I, Papalexandris N. The impact of M\&A experience on strategic HRM practices and organisational effectiveness: evidence from Greek firms. Hum Resour Manage J. 2007;17(2):155-177. doi: 10.1111/j.1748-8583.2007.00031.x

3. Pablos POd. Strategic human resource management and organisational competitiveness: the importance of fit and flexibility. Int J Hum Resour Dev Manage. 2005;5(1). doi: 10.1504/ijhrdm.2005.005982

4. Aisbett L, Hoye R. Human resource management practices to support sport event volunteers. Asia P J Hum Resour. 2015;53(3):351-369. doi: 10.1111/1744-7941.12062

5. Taylor T, McGraw P. Exploring human resource management practices in nonprofit sport organisations. Sport Manage Rev. 2006;9(3):229-251.

6. Bauer HH, Sauer NE, Schmitt P. Customer-based brand equity in the team sport industry. European J Mark. 2005;39(5/6):496-513. doi: 10.1108/03090560510590683

7. Unlu C, Serarslan MZ, Yamaner F, Sahin S. Comparing of Human Resources Management Sports Enterprises and the Other Service Enterprises. Procedia Soc Behav Sci. 2012;46:4808-4812. doi: 10.1016/j.sbspro.2012.06.339

8. Khasawneh S. Human capital planning in higher education institutions. Int J Educ Manage. 2011;25(6):534-544. doi: 10.1108/09513541111159040

9. Bulla DN, Scott PM. Manpower requirements forecasting: a case example. Strategic Human Resource Planning Applications. Boston: Springer; 1987. p. 145-155.

10.Guthrie JP. High-Involvement Work Practices, Turnover, and Productivity: Evidence from New Zealand. Acad Manage J. 2001;44(1):180-190. doi: 10.5465/3069345

11.Long C-S. Examining Human Resource Competencies and Their Relationship to the Success Factors of HR Profession. J Serv Sci Manage. 2008;01(03):259-265. doi: 10.4236/jssm.2008.13029

12. Tseng ST, Levy PE. A multilevel leadership process framework of performance management. Hum Resour Manage Rev. 2019;29(4). doi: 10.1016/j.hrmr.2018.10.001

13.Johansen MS, Sowa JE. Human resource management, employee engagement, and nonprofit hospital performance. Nonprofit Manage Leadersh. 2019;29(4):549-567. doi: 10.1002/nml.21352

14. Tripolitsioti A. Human Resource Management characteristics of the Olympic sports organizations Global Journal of Human Resource Management2017. 61-72 p.

15.Johnson G, Scholes K. Exploring Corporate Strategy, Prentice Hall. New Delhi: Prentice Hall; 2002.

16. Hunger J, D WTL. Essentials of Strategic Management: Pearson; 2010.

17. Brauns M. Aligning Strategic Human Resource Management To Human Resources, Performance And Reward. Int Bus Econ Res J (IBER). 2013;12(11). doi: 10.19030/iber.v12i11.8179

18. Trainer JF. Models and tools for strategic planning. New Dir Institutl Res. 2004;2004(123):129-138. doi: 10.1002/ir.127

19. Griffith DA, Kiessling T, Dabic M. Aligning strategic orientation with local market conditions. Int Mark Rev. 2012;29(4):379-402. doi: 10.1108/02651331211242629

20. Akingbola K. Contingency, fit and flexibility of HRM in nonprofit organizations. Employee Relat. 2013;35(5):479-494. doi: 10.1108/er-01-2012-0009

21.Hanlon C, Cuskelly G. Pulsating Major Sport Event Organizations: A Framework for Inducting Managerial Personnel. Event Manage. 2002;7(4):231-243. doi: 10.3727/152599502108751622

22. Nova J. Teaching Human Resources in Sport Management by Emphasizing the Strategic Focus. The Turkish Online Journal of Educational Technology 2017.

23.Lee HW, Pak J, Kim S, Li L-Z. Effects of Human Resource Management Systems on Employee Proactivity and Group Innovation. J Manage. 2016;45(2):819-846. doi: 10.1177/0149206316680029

24. Aviso KB, Chiu ASF, Demeterio FPA, Lucas RIG, Tseng M-L, Tan RR. Optimal human resource planning with P-graph for universities undergoing transition. J Cleaner Prod. 2019;224:811-822. doi: 10.1016/j.jclepro.2019.03.213

25.Al-Ayed SI. The impact of strategic human resource management on organizational resilience: an empirical study on hospitals. Bus Theory Pract. 2019;20:179-186. doi: 10.3846/btp.2019.17 
26. Omer S. SWOT analysis implementation's significance on strategy planning Samsung mobile company as an example. J Process Manage New Technol. 2019;7(1):56-62. doi: 10.5937/jouproman7-20167

27. Gholami B. An Appraisal of the Role of Strategic Management Tools in Strategic Human Resource Planning. Hum Res Manag Res. 2017;9(2):119-142.

28. Shams MR, Khanmohammadi MH, Kordlooyi HR. Combined Design of SWOT and QFD Methods in Developing Business Strategies in Economic Situation (Case Study: Iran Packaging Company). J Account Knowledge Manage Audi. 2018;3(25):239- 250.

29.Javadipour M, Rahbari S. Pathology of the Policy-Making Process in Sport for All in Iran. Ann Appl Sport Sci. 2018;6(3):61-72. doi: 10.29252/aassjournal.6.3.61

30. Marler JH, Fisher SL. An evidence-based review of e-HRM and strategic human resource management. Hum Res Manag Rev. 2013;23(1):18-36. doi: 10.1016/j.hrmr.2012.06.002

31. Çınar O, Karcıoğlu F. The Relationship between Strategic Management, Institutionalization and Human Resource Management: A Survey Study with Family Businesses Located in the Northeast Anatolia Sub Economic Region of Turkey. Procedia Soc Behav Sci. 2013;99:835-842. doi: 10.1016/j.sbspro.2013.10.555

32. Motalebi VA. The effect of strategic management of human resource on the performance of Islamic Republic of Iran Navy Employees (Case Study: Imam Khomeini Marine Science University). J Teach Mar Sci. 2016;3(5):28 - 39.

33. Aarabi S, Armanpour M. Developing Human Resources Strategy Using QFD Approach in Transport and Terminals Organization. Indust Manag Stud. 2004;2(7):57-81.

34. Abasi A, Mosleh Shirazi AN, Hoseini F. Developing Human Resource Strategy Coherent with Business Strategies, Culture and Organizational Structure. Hum Res Manag Res. 2017;9(2):21-46.

35. Caldwell C, Truong DX, Linh PT, Tuan A. Strategic Human Resource Management as Ethical Stewardship. J Bus Ethics. 2010;98(1):171-182. doi: 10.1007/s10551-010-0541-y

36. Weerakoon RK. Human Resource Management in Sports: A Critical Review of its Importance and Pertaining Issues. Phys Cult Sport Stu Res. 2016;69(1):15-21. doi: 10.1515/pcssr-2016-0005

37. Alexander Di Pofi J. Organizational diagnostics: integrating qualitative and quantitative methodology. $J$ Organ Change Manage. 2002;15(2):156-168. doi: 10.1108/09534810210423053

38. Santos NdM, Bronzo M, Oliveira MPVd, Resende PTVd. Organizational Culture, Organizational Structure and Human Resource Management as Bases for Business Process Orientation and their Impacts on Organizational Performance. Braz Bus Rev. 2014;11(3):100-122. doi: 10.15728/bbr.2014.11.3.5

39. Aslam HD, Aslam M, Ali N, Habib B. Importance of Human Resource Management in 21st Century: A Theoretical Perspective. Intl J Hum Res Stu. 2014;3(3). doi: 10.5296/ijhrs.v3i3.6255 